\title{
Study of Forest Cover Change Dynamics between 2000 and 2015 in the Ikongo District of Madagascar Using Multi-Temporal Landsat Satellite Images
}

\author{
Aimé Richard Hajalalaina ${ }^{1,2,3}{ }^{*}$, Arisetra Razafinimaro',2,3, Nicolas Ratolotriniaina ${ }^{3}$ \\ ${ }^{1}$ Department of Computer Science, Ecole de Management et d'Innovation Technologique (EMIT), University of Fianarantsoa, \\ Fianarantsoa, Madagascar \\ ${ }^{2}$ Laboratoire d'Informatique et des Mathématiques Appliqués au Développement (LIMAD), University of Fianarantsoa, \\ Fianarantsoa, Madagascar \\ ${ }^{3}$ Informatique-Géomatique, Mathematiques et Applications (IGMA), University of Fianarantsoa, Fianarantsoa, Madagascar \\ Email: *arhajalalaina@yahoo.fr
}

How to cite this paper: Hajalalaina, A.R., Razafinimaro, A. and Ratolotriniaina, N. (2021) Study of Forest Cover Change Dynamics between 2000 and 2015 in the Ikongo District of Madagascar Using MultiTemporal Landsat Satellite Images. $A d$ vances in Remote Sensing, 10, 78-91. https://doi.org/10.4236/ars.2021.103005

Received: July 22, 2021

Accepted: August 23, 2021

Published: August 26, 2021

Copyright $\odot 2021$ by author(s) and Scientific Research Publishing Inc. This work is licensed under the Creative Commons Attribution International License (CC BY 4.0).

http://creativecommons.org/licenses/by/4.0/

\begin{abstract}
Satellite images are considered reliable data that preserve land cover information. In the field of remote sensing, these images allow relevant analyses of changes in space over time through the use of computer tools. In this study, we have applied the "discriminant" change detection algorithm. In this, we have verified its effectiveness in multi-temporal studies. Also, we have determined the change in forest dynamics in the Ikongo district of Madagascar between 2000 and 2015. During the treatments, we have used the Landsat TM satellite images for the years 2000, 2005 and 2010 as well as ETM+ for 2015. Thus, analyses carried out have allowed us to note that between 2000-2005, $1.4 \%$ of natural forest disappeared. And, between 2005-2010, forests degradation was $1.8 \%$. Also, between $2010-2015$, about $0.5 \%$ of the natural forest conserved in 2010 disappeared. Furthermore, we have found that the discriminant algorithm is considerably efficient in terms of monitoring the dynamics of forest cover change.
\end{abstract}

\section{Keywords}

Remote Sensing, Image Processing, Change Detect, Multi-Temporal, Landsat, Forest Covert

\section{Introduction}

Since the last two decades, remote sensing has been widely used to detect changes 
in phenomena such as urban areas, land cover and also in forest cover [1] [2] [3] [4]. On the one hand, thanks to the availability of satellite imagery researchers can perform not only multi-temporal but also time series change studies [5] [6]. On the other hand, computer-based techniques are able to determine the effects of a phenomenon in an area at different dates [7] [8]. Then, the change detection algorithm is one of the techniques that can carry out this work. Moreover, its main operation makes feasible the analysis of before and after situation in a surface [9]. Undoubtedly, the forestry domain really requires the intervention of the change detection algorithm to quantify changes.

For Madagascar, the study based on satellite image processing started since the year 80. It was a vegetation study conducted by [10] as part of his thesis. A few years later, analyses applied to forest cover were carried out by scientific researchers with the aim of verifying hypotheses. In general, these works are divided into two categories such as national works doing image processing of the whole of Madagascar like the works [11] [12], as well as specific studies targeting one or a few study areas like the works of [13]. Furthermore, it seems that most of these studies focus on the evolution or assessment of changes in forest cover [14] [15], although the forest area of this country is decreasing due to massive exploitation in the forest zone, charcoal and especially tavy cultivation [16] [17].

In this study, we focus particularly on the use of the Erdas Imagine "Discriminant function change" algorithm because this algorithm is not only efficient but it is also often used to detect the following change in time [18]. Our objectives are not only to evaluate the effectiveness of this algorithm on the study of dynamics of change but also to quantify the deforestation of the Ikongo District of Madagascar over 15 years. Secondly, we will use Landsat TM satellite image for the year 2000, 2005, 2010 and also a Landsat ETM+ satellite image for the year 2015 of this study area. Thus, in order to carry out this study, we will define four parts. Firstly, we will discuss the materials and methods. Secondly, we will present the results obtained on the classifications and also we will show the results of the change detection of the year 2000-2005, 2005-2010, 2010-2015. Thirdly, we will discuss the results obtained. Finally, we will make the conclusion.

\section{Materials and Methods}

\subsection{Study Area}

Ikongo District is a district of the Vatovavy Region, located in the South East of Madagascar. Subsequently, this district is found on the point of coordinates $21^{\circ} 52^{\prime} 59^{\prime \prime}$ and $47^{\circ} 25^{\prime} 59^{\prime \prime}$ while its altitude is at $280 \mathrm{~m}$. According to (SaryTany and Someah, 2012), this study area has a perhumid type bioclimate. Figure 1 shows us our study area.

\subsection{Satellite Images Used}

In the case of this study, we will use images from the Landsat $5 \mathrm{TM}$ sensor and 


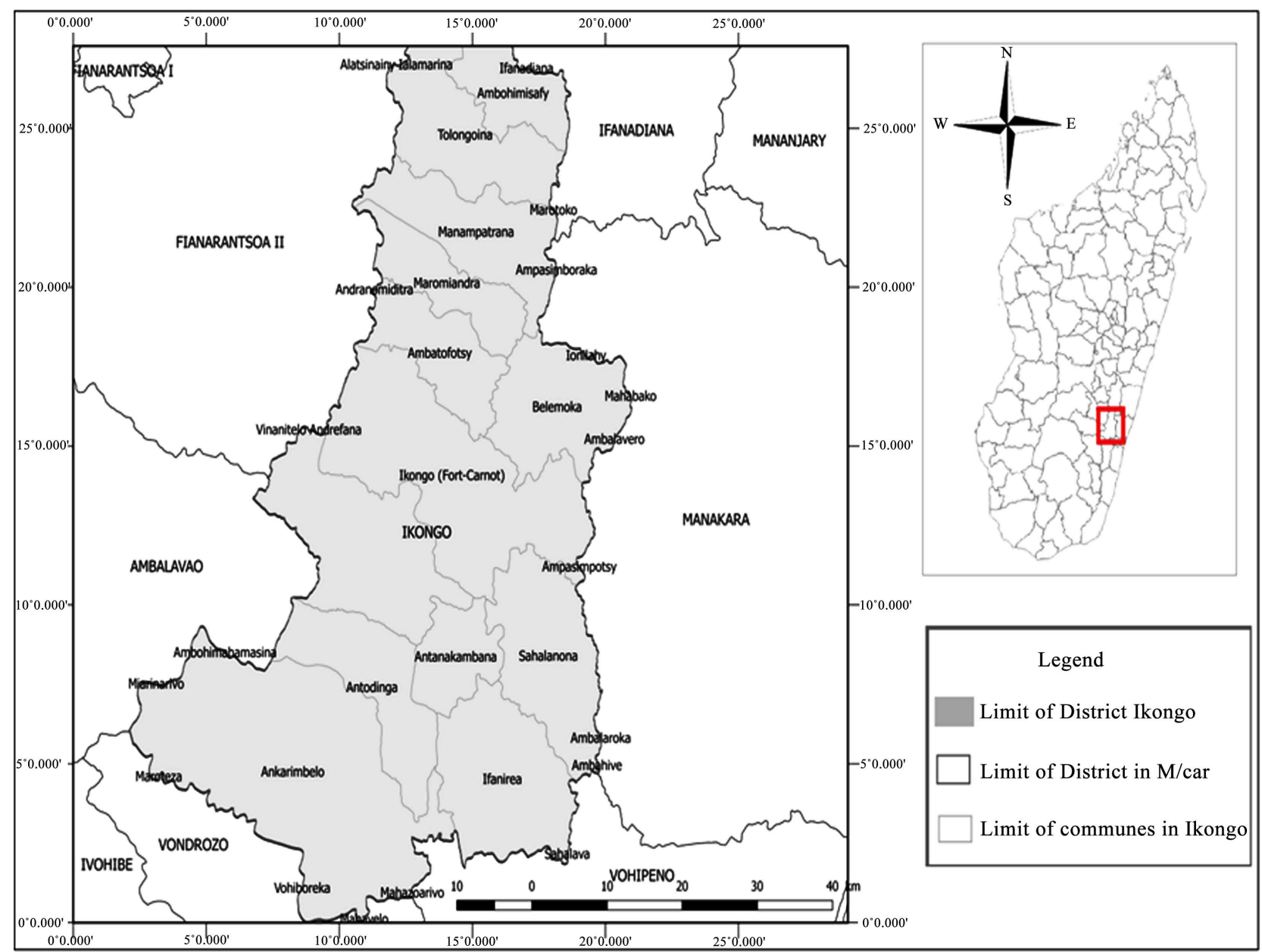

Figure 1. Study area of district Ikongo in Madagascar.

Landsat 7 ETM+ sensor. These images are all freely downloadable from the link https://earthexplorer.usgs.gov/. In general, these two satellites have remarkable characteristics in terms of the number of spectral bands and also the presence of panchromatic bands, especially for the ETM+ sensor. Table 1 presents more information about the characteristics of the images used.

We chose these images because they are not only free of charge but also present very nice spectral information and are suitable for land cover dynamics [19] [20] [21]. Secondly, we selected images with a very low percentage of clouds in order to produce more or less reliable results. This is why we took the image of the months of February 2000, March 2005, January 2010 and February 2015.

\subsection{Methodology for Change Detection}

Firstly, the realisation of forest area change dynamics is a multi-step process [22], as all steps add value to the accuracy of the final results. All steps add value to the accuracy of the final results and may vary depending on the area to be studied and the choice of methodology. In our case, we choose to establish our treatments in three phases which are pre-processing, classification and then 
Table 1. Characteristics of the images used.

\begin{tabular}{|c|c|c|c|c|c|}
\hline \multirow{2}{*}{ Path/Row } & \multirow{2}{*}{$\begin{array}{c}\text { Date of } \\
\text { acquisition }\end{array}$} & \multirow{2}{*}{ Sensor } & \multicolumn{3}{|c|}{ Spectral bands } \\
\hline & & & Band & Spectral band & Resolution \\
\hline \multirow{7}{*}{$158 / 75$} & \multirow{7}{*}{$02 / 02 / 2015$} & \multirow{7}{*}{ ETM+ } & 1 (Blue) & $0.45-0.515$ & 30 \\
\hline & & & 2 (Green) & $0.52-0.605$ & 30 \\
\hline & & & 3 (Red) & $0.63-0.69$ & 30 \\
\hline & & & 4 (Infrared) & $0.76-0.90$ & 30 \\
\hline & & & 5 (Infrared) & $1.55-1.75$ & 30 \\
\hline & & & 6 (Thermic Infrared) & $10.42-12.50$ & 60 \\
\hline & & & 7 (Infrared) & $2.09-2.35$ & 30 \\
\hline \multirow{7}{*}{$158 / 75$} & \multirow{7}{*}{$\begin{array}{l}2 / 02 / 2000 \\
3 / 03 / 2005 \\
2 / 01 / 2010\end{array}$} & \multirow{7}{*}{ TM } & 1 (Blue) & $0.45-0.52$ & 30 \\
\hline & & & 2 (Green) & $0.52-0.60$ & 30 \\
\hline & & & 3 (Red) & $0.63-0.69$ & 30 \\
\hline & & & 4 (Infrared) & $0.76-0.90$ & 30 \\
\hline & & & 5 (Infrared) & $1.55-1.75$ & 30 \\
\hline & & & 6 (Thermic Infrared) & $10.42-12.50$ & 60 \\
\hline & & & 7 (Infrared) & $2.08-2.35$ & 30 \\
\hline
\end{tabular}

post-classification [23]. In general, this method is commonly used in satellite image processing.

Pre-processing: This phase focuses mainly on the consideration of spectral, radiometric and spatial aspects of the images, as these treatments strongly contribute to the quality of the expected results [24]. First, we will combine the spectral bands of each date to form multi-spectral images. Second, we will use the radiometric correction for our images because this is a pre-processing to improve the spectral value of a satellite image taken by a sensor. Then, this process allows the normalization of images acquired in different dates and different sources necessary for the detection of change [25]. Since, the latter requires common features as much as possible between the images to be compared [26]. Consequently, their radiometric corrections are essential to find reliable results to the change. Then, in ERDAS Imagine we will use the contrast stretching for doing those. Similarly, we will make geometric correction to ensure the superposition of the images to be compared [27]. Thus, we will make the geometric correction with method of GCP (Ground Control Points), i.e. the use of references on the earth's surface such as the intersection of the road or also objects that do not move with time but are shown on the image, as reference points during the correction. And, we will use the true colour and false colour function to make the visual analysis easy during the supervised classification of our images [28].

Classification: Since we want to analyse the evolution of the forest in our study area therefore it is important to perform supervised classification on each image to properly categorise these objects. Furthermore, this step arranges compatibili- 
ties between these images during the comparison in the change detection phase [29]. Thus, we define two object categories which include natural forest and open space. For this purpose, we choose the maximum likelihood the fact that this algorithm is one of the well-known supervised classification methods used in the world of satellite image processing [30] [31] [32]. Moreover, this method is based on the probability that a pixel belongs to a particular class. That is, a pixel is classified in the corresponding class when it has the maximum probability for that class. However, it uses the probability function as the decision rule used. In other words, the maximum likelihood classifier quantitatively evaluates the variance and covariance of the spectral response patterns when classifying an unknown pixel.

$$
\hat{p}\left(x \mid w_{i}\right)=\frac{1}{(2 \pi)^{\frac{1}{2}} \hat{\sigma}_{i}} \exp \left[-\frac{1}{2} \frac{\left(x-\hat{u}_{i}\right)^{2}}{\hat{\sigma}_{i}^{2}}\right]
$$

where $x$. value of the brightness of the axis of $x$

$\hat{u}_{i}$ : mean value of the classes

$\hat{\sigma}_{i}$ : measure of the variance of the classes

Detection change: In order to perform change detection for our study area, we rely on the "bi-temporal data" type [27] [34], i.e. a method based on the comparison of two satellite images of different dates. Thus, we take the "Discriminant Function Change" of Erdas as the change detection algorithm. This method is particularly based on the calculation of the probability of the change of pixel by pixel of two images of the same area and different dates [35]. It consists of 6 steps [36]. First, the base image between the two input images is determined. Then, unsupervised classification of this base image into a reasonable number of spectral classes (64 - 128 classes) is performed. Then, the multivariate signatures (Mean Vector, M, and Cov) of the other image are extracted using the image from the unsupervised classification, which is called "classbase" and the output of this step is "image change". Then, we apply the Mahalanobis distance calculation to each pixel of the image change using the signature corresponding to the class to which it belongs. In the end, the algorithm converts the MD metric into a probability and then we can have an output image from this probability. The pixel values of this image are between 0.0 and 1.0. This conversion and final image output adopts the "Chi-Square Transformation" technique [27] of change detection. Figure 2 shows the steps required to carry out these treatments.

\section{Results}

Following the pre-processing we did for our images, we also performed classifications using the maximum likelihood algorithm as shown in our methodology. Then, we validated the results by using the google earth image of the same date in each image. As a result, we obtained the best results shown in Figure 3.

Each result of our classifications is associated with an Overall Classification Accuracy and a kappa index. For the year 2000, we have an Overall Classification 


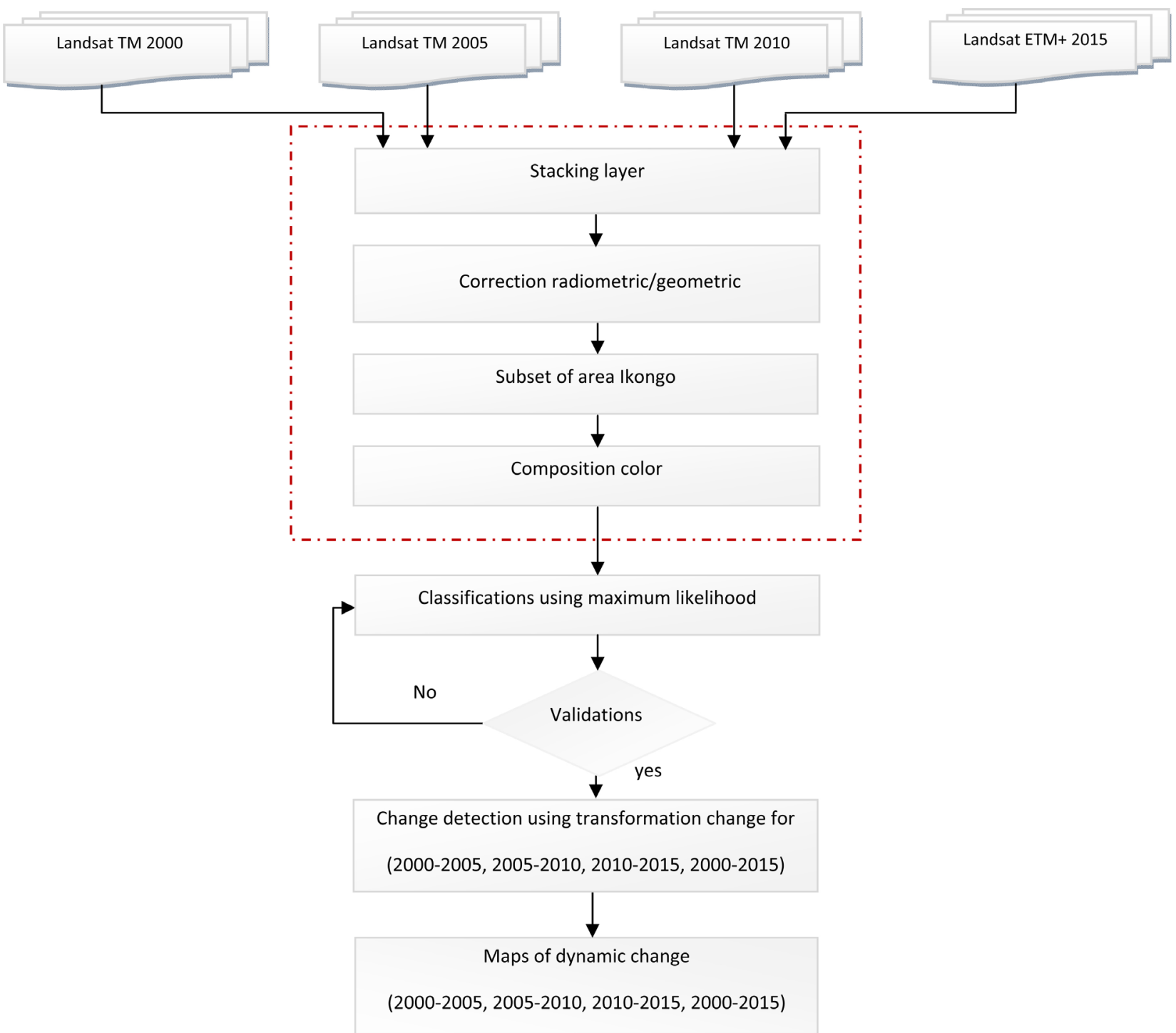

Figure 2. Methodology for change detection using multi-temporal images.

Accuracy of $94.44 \%$ and a Kappa index of 0.8875 . Subsequently, we obtained 94.59\% Overall Classification Accuracy and 0.8902 kappa index for the year 2005. For the year 2010, we have an Overall Classification Accuracy equal to $94.59 \%$ and 0.8902 of kappa index. For the year 2015, we obtained $92.31 \%$ Overall Classification Accuracy and 0.8462 kappa index. In addition, the accuracy assessment results are shown in Tables 2-5.

To achieve the objective of multi-temporal analysis in this study, we compared the image of 2000 and 2005, 2005 and 2010, 2010 and 2015 and 2000 and 2015 for further discussion. These comparisons gave us four dynamic maps that present the natural forest, open space, forest loss and forest appearance of our study area according to these years. The results of these treatments are presented in Figure 4.

In order to examine the values of these changes we have performed the area calculation for each object in each image. Thus we quantified the following values. 
Table 2. Accuracy assessment result of classified image 2000.

\begin{tabular}{cccccc}
\hline Class Name & $\begin{array}{c}\text { Reference } \\
\text { Totals }\end{array}$ & $\begin{array}{c}\text { Classified } \\
\text { Totals }\end{array}$ & $\begin{array}{c}\text { Number } \\
\text { Correct }\end{array}$ & $\begin{array}{c}\text { Producers } \\
\text { Accuracy }\end{array}$ & $\begin{array}{c}\text { Users } \\
\text { Accuracy }\end{array}$ \\
\hline No classified & - & - & - & - & - \\
Forest & 20 & 20 & 19 & $95.00 \%$ & $95.00 \%$ \\
Prairie & 16 & 16 & 15 & $93.75 \%$ & $93.75 \%$ \\
Totals & 36 & 36 & 34 & & \\
\hline
\end{tabular}

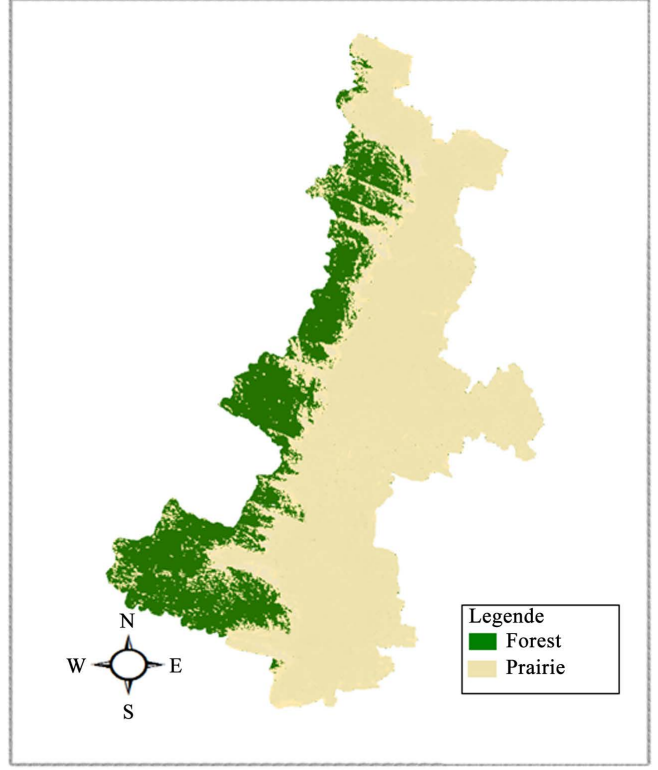

(a)

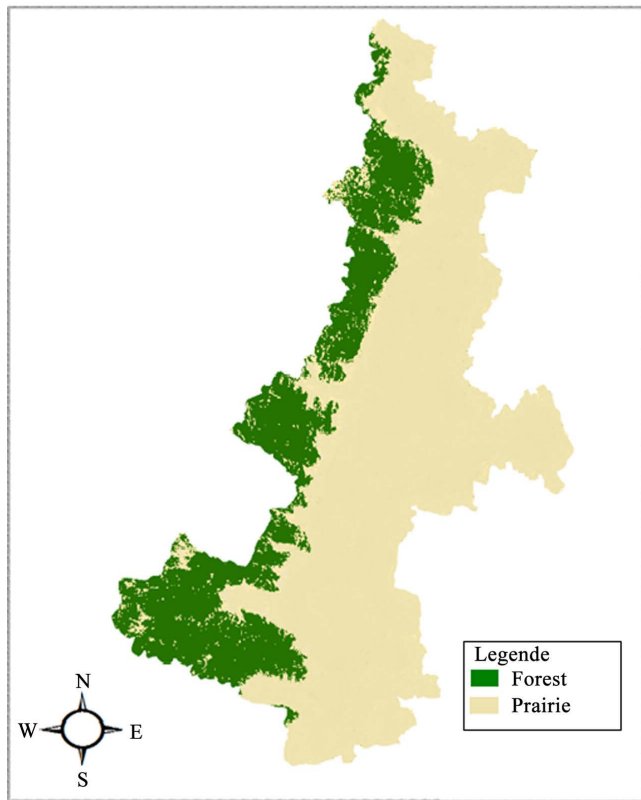

(c)

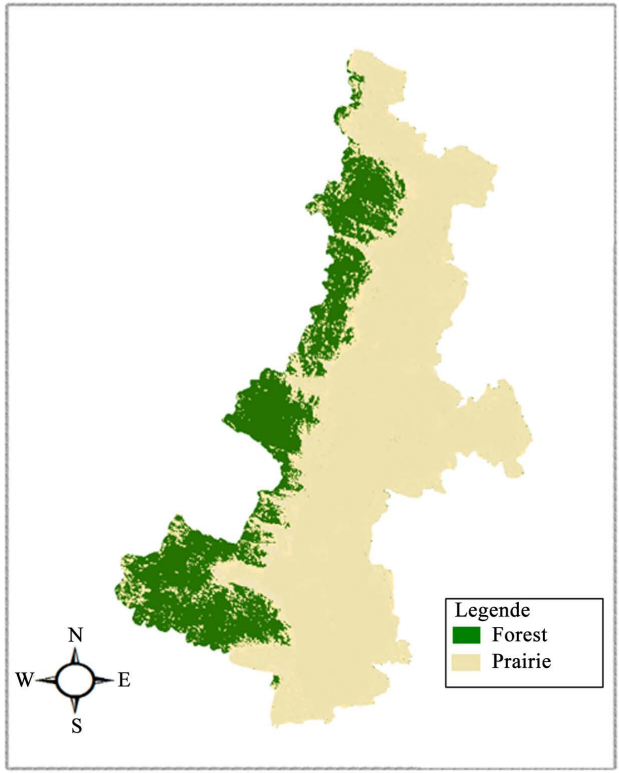

(b)

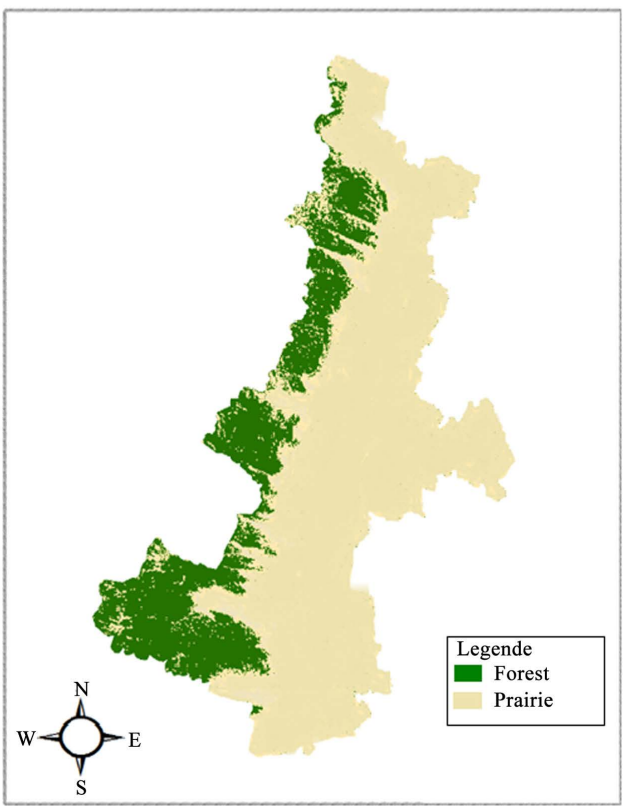

(d)

Figure 3. Results of the Ikongo district classification using Maximum Likelihood 2000 (a), 2005 (b), 2010 (c) and 2015 (d). 
Table 3. Accuracy assessment result of classified image 2005.

\begin{tabular}{cccccc}
\hline Class Name & $\begin{array}{c}\text { Reference } \\
\text { Totals }\end{array}$ & $\begin{array}{c}\text { Classified } \\
\text { Totals }\end{array}$ & $\begin{array}{c}\text { Number } \\
\text { Correct }\end{array}$ & $\begin{array}{c}\text { Producers } \\
\text { Accuracy }\end{array}$ & $\begin{array}{c}\text { Users } \\
\text { Accuracy }\end{array}$ \\
\hline No classified & - & - & - & - & - \\
Forest & 22 & 20 & 20 & $90.91 \%$ & $100.00 \%$ \\
Prairie & 15 & 17 & 15 & $100.00 \%$ & $88.24 \%$ \\
Totals & 37 & 37 & 35 & & \\
\hline
\end{tabular}
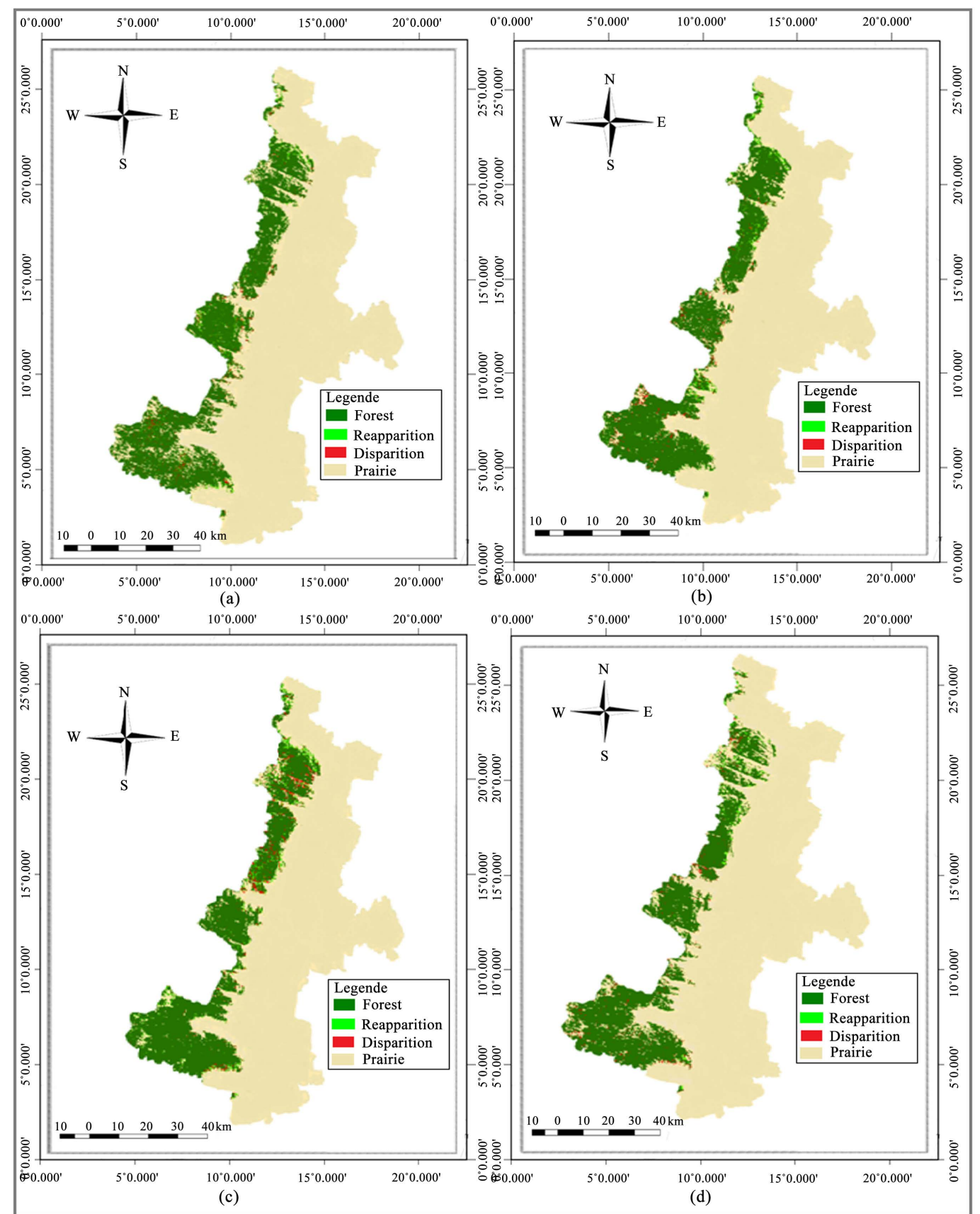

Figure 4. Change detection results of 2000-2005 (a), 2005-2010 (b), 2010-2015 (c) and 2000-2015 (d) of Ikongo District. 
Table 4. Accuracy assessment result of classified image 2010.

\begin{tabular}{cccccc}
\hline Class Name & $\begin{array}{c}\text { Reference } \\
\text { Totals }\end{array}$ & $\begin{array}{c}\text { Classified } \\
\text { Totals }\end{array}$ & $\begin{array}{c}\text { Number } \\
\text { Correct }\end{array}$ & $\begin{array}{c}\text { Producers } \\
\text { Accuracy }\end{array}$ & $\begin{array}{c}\text { Users } \\
\text { Accuracy }\end{array}$ \\
\hline No classified & - & - & - & - & - \\
Forest & 17 & 15 & 15 & $88.24 \%$ & $100.00 \%$ \\
Prairie & 20 & 22 & 20 & $100.00 \%$ & $90.91 \%$ \\
Totals & 37 & 37 & 35 & & \\
\hline
\end{tabular}

Table 5. Accuracy assessment result of classified image 2015.

\begin{tabular}{cccccc}
\hline Class Name & $\begin{array}{c}\text { Reference } \\
\text { Totals }\end{array}$ & $\begin{array}{c}\text { Classified } \\
\text { Totals }\end{array}$ & $\begin{array}{c}\text { Number } \\
\text { Correct }\end{array}$ & $\begin{array}{c}\text { Producers } \\
\text { Accuracy }\end{array}$ & $\begin{array}{c}\text { Users } \\
\text { Accuracy }\end{array}$ \\
\hline No classified & - & - & - & - & - \\
Forest & 13 & 13 & 12 & $92.31 \%$ & $92.31 \%$ \\
Prairie & 13 & 13 & 12 & $92.31 \%$ & $92.31 \%$ \\
Totals & 26 & 26 & 24 & & \\
\hline
\end{tabular}

Between 2000-2005, approximately 64,236.4 hectares of natural forest in Ikongo District were recorded in 2000, of which 63,532.9 hectares were preserved in 2005, which means that 912.2 hectares or $1.4 \%$ had disappeared. On the other hand, there is an appearance of forest equal to 208.8 ha. Between 2005-2010, the area of natural forest decreases to 63,111.2 ha, of which the degradation is $1120.6 \mathrm{ha}$, which gives $1.8 \%$ of the natural forest in 2005 . The appearance is 699 ha. Between 2010-2015, the area of natural forest conserved is equal to $63,946.6$ ha of which the degradation is 334 ha which gives $0.5 \%$ of the natural forest conserved in 2010. However, the appearance of forest increases to 1169.4 ha. Table 6 shows the results of these calculations.

In order to illustrate the trend of this evolution, we have drawn a curve of disappearance and appearance corresponding to these data and we have also drawn a curve indicating the evolution of the natural forest area during these study years. Figure 5 and Figure 6 show these results in graphical form.

With respect to the methodology we have taken, we can say that our results are accurate in the context of change detection because we have done the radiometric and geometric correction which are really essential for change detection between two satellite images. In addition, we have normalised our data using supervised classification. These lead to the reliability of the comparison of multi-temporal images apart from the efficiency of the discriminant algorithm.

From the results obtained, it is undeniable that the function change discriminant algorithm is highly capable of searching for differences between the two input images. However, the processing takes a lot of time due to the instructions performed by this algorithm such as unsupervised classification before proceeding with the comparison. Furthermore, the user must understand the meaning of each parameter used by this algorithm to ensure its efficiency. 


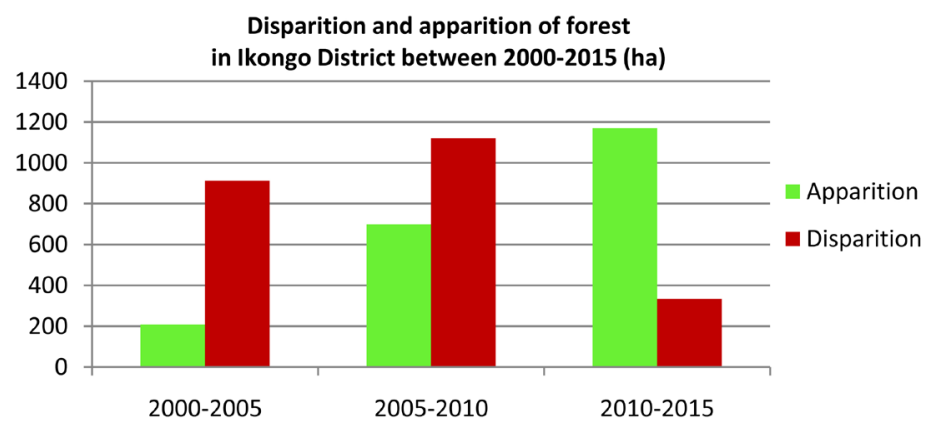

Figure 5. Histogram showing the dynamics of the Ikongo forest between 2000-2015.

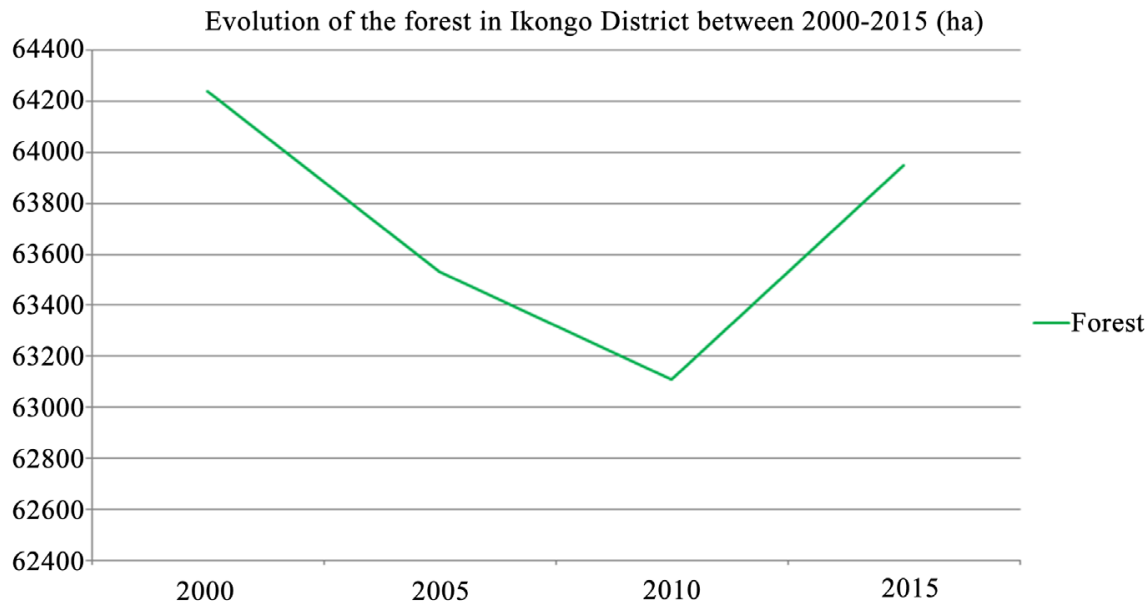

Figure 6. Graphical of the evolution of the Ikongo forest between 2000-2015.

Table 6. Results of forest dynamics calculations.

\begin{tabular}{cccc}
\hline & $2000-2005$ & $2005-2010$ & $2010-2015$ \\
\cline { 2 - 4 } & Total (ha) & Total (ha) & Total (ha) \\
\hline Apparition & 208.8 & 699 & 1169.4 \\
Disparition & 912.2 & 1120.6 & 334 \\
Naturel forest & $63,532.9$ & $63,111.2$ & $63,946.6$ \\
Results & -703.5 & -421.7 & +835.4 \\
\hline
\end{tabular}

The season of image acquisition and the percentage of cloud, play a very important role in the quality of the results of the forest dynamics change detection since they can easily distort the estimation results. Also, the surface area of the study area obviously corresponds to the functioning of the discriminant algorithm, since this algorithm works on the pixel, which means that the larger the matrix to be processed, the longer the processing time.

Between 2000-2015, natural forests have suffered a loss of about 289 ha of its surface. Indeed, these losses correspond not only to the number of people in the study area but also to the activities of these inhabitants. According to [37], Ikongo District is part of the populated area in the Vatovavy Fito vinany Region, while $85 \%$ of the population in this region practice agriculture. In addition, the popu- 
lation in this region also uses tavy cultivation to expand their agricultural areas. These acts contribute greatly to deforestation in this study area.

\section{Conclusion}

In conclusion, our study focuses on the implementation of the function change discriminant algorithm to detect change in the natural forest dynamics of Ikongo District. We set a main objective to evaluate the efficiency of this algorithm by analysing Multi-temporal satellite images. In this, we took Landsat images from the TM sensor for the year 2000, 2005 and 2010 and from the ETM+ sensor for the year 2005. The processing was done in three phases which are preprocessing, classification and change detection. In addition, we used ERDAS Imagine as the image processing software. In addition, we also quantified the natural forest evolution, degradation and appearance that were found during the treatments for the date 2000, 2005, 2010 and 2015. Thus, the result of this research shows that the discriminant algorithm is effective in detecting changes in natural forest dynamics. It is perfectly capable of comparing two images of different dates. From the results obtained, we can conclude that between 2000-2015 Ikongo District lost 289 ha of natural forest by comparing the total forest in 2000 to 2015 . We also found that each year of image processing we found more appearance of forest especially between the year 2010-2015. Thus, we can also say that this appearance saves the existing degradation in this area. In addition, the majority of the population in this area is engaged in agriculture as their main activity. Intuitively, the latter contributes a lot to this degradation.

\section{Conflicts of Interest}

The authors declare no conflicts of interest regarding the publication of this paper.

\section{References}

[1] Moghimi, A., Mohammadzadeh, A. and Khazai, S. (2017) Integrating Thresholding with Level Set Method for Unsupervised Change Detection in Multitemporal SAR Images. Canadian Journal of Remote Sensing, 43, 412-431. https://doi.org/10.1080/07038992.2017.1342205

[2] Nie, Q., Man, W., Li, Z. and Huang, Y. (2016) Spatiotemporal Impact of Urban Impervious Surface on Land Surface Temperature in Shanghai, China. Canadian Journal of Remote Sensing, 42, 680-689. https://doi.org/10.1080/07038992.2016.1217484

[3] Hermosilla, T., Wulder, M.A., White, J.C., Coops, N.C. and Hobart, G.W. (2018) Disturbance-Informed Annual Land Cover Classification Maps of Canada's Forested Ecosystems for a 29-Year Landsat Time Series. Canadian Journal of Remote Sensing, 44, 67-87. https://doi.org/10.1080/07038992.2018.1437719

[4] Verbesselt, J., Hyndman, R., Newnham, G. and Culvenor, D. (2010) Detecting Trend and Seasonal Changes in Satellite Image Time Series. Remote Sensing of Environment, 114, 106-115. https://doi.org/10.1016/j.rse.2009.08.014

[5] Devries, B., Decuyper, M., Verbesselt, J., Zeileis, A., Herold, M. and Joseph, S. 
(2015) Tracking Disturbance-Regrowth Dynamics in Tropical Forests Using Structural Change Detection and Landsat Time Series. Remote Sensing of Environment, 169, 320-334. https://doi.org/10.1016/j.rse.2015.08.020

[6] Liu, J., Heiskanen, J., Aynekulu, E., Maeda, E.E. and Pellikka, P.K. (2016) Land Cover Characterization in West Sudanian Savannas Using Seasonal Features from Annual Landsat Time Series. Remote Sensing, 8, 365-382. https://doi.org/10.3390/rs8050365

[7] Karantzalos, K. (2015) Recent Advances on 2D and 3D Change Detection in Urban Environments from Remote Sensing Data. In: Helbich, M., Arsanjani, J.J. and Leitner, M., Eds., Computational Approaches for Urban Environments, Springer, Berlin, 237-272. https://doi.org/10.1007/978-3-319-11469-9 10

[8] Macleod, R.D. and Congalton, R.G. (1998) A Quantitative Comparison of ChangeDetection Algorithms for Monitoring Eelgrass from Remotely Sensed Data. Photogrammetric Engineering \& Remote Sensing, 64, 207-216.

[9] Andrianarivo, A., Delaître, E., Laques, A.-E., Carrière, S.M. and Hervé, D. (2015) Détection de changement de l'occupation du sol dans une commune à la périphérie de la forêt humide de Fianarantsoa. Transitions agraires au sud de Madagascar: Résilience et viabilité, deux facettes de la conservation.

[10] Faramalala, M.H. (1988) Etude de la végétation de Madagascar à l'aide de données spatiales. Thèse en Sciences biologiques fondamentales et appliqués. Université Paul Sabatier, Toulouse, $172 \mathrm{p}$.

[11] Mayaux, P., Gond, V. and Bartholomé, E. (2000) A Near-Real Time Forest-Cover Map of Madagascar Derived from SPOT-4 VEGETATION Data. International Journal of Remote Sensing, 21, 3139-3144. https://doi.org/10.1080/01431160050145018

[12] Du Puy, D.J. and Moat, J. (2003) Using Geological Substrate to Identify and Map Primary Vegetation Types in Madagascar and the Implications for Planning Biodiversity Conservation. In: Goodman, S.M. and Benstead, J.P., Eds., The Natural History of Madagascar, University of Chicago Press, Chicago, 51-74.

[13] Hajalalaina, A.R., Grizonnet, M., Delaitre, E., Rakotondraompiana, S. and Hervé, D. (2013) Discrimination des zones humides en foret Malgache, proposition d'une methodologie multiresolution et multisource utilisant orfeo toolbox. Revue de Photogrammetrie et de télédétection.

[14] Harper, G.J., Steininger, M.K., Tucker, C.J., Juhn, D. and Hawkins, F. (2007) Fifty Years of Deforestation and Forest Fragmentation in Madagascar. Environmental Conservation, 34, 325-333. https://doi.org/10.1017/S0376892907004262

[15] ONE (2013) Evolution de la couverture des forêts naturelles à Madagascar, 20052010. Rapport, 48 p.

[16] Brooks, C.P., Holmes, C., Kramer, K., Barnett, B. and Keitt, T.H. (2009) The Role of Demography and Markets in Determining Deforestation Rates near Ranomafana National Park, Madagascar. PLoS ONE, 4, e5783.

[17] Zinner, D., Wygoda, C., Razafimanantsoa, L., et al. (2014) Analysis of Deforestation Patterns in the Central Menabe, Madagascar, between 1973 and 2010. Regional Environmental Change, 14, 157-166. https://doi.org/10.1007/s10113-013-0475-x

[18] Im, J., Jensen, J.R. and Hodgson, M.E. (2008) Optimizing the Binary Discriminant Function in Change Detection Applications. Remote Sensing of Environment, 112, 2761-2776.

[19] Oszwald, J., Lefebvre, A., Arnauld de Sartre, X., Thalès, M. and Gond, V. (2010) Analyse des directions de changement des états de surface végétaux pour renseigner 
la dynamique du front pionnier de Maçaranduba (Para, Brésil) entre 1997 et 2006. Télédétection, 9, 97-111.

[20] Margono, B.A., Turubanova, S., Zhuravleva, I., Potapov, P., Tyukavina, A., Baccini, A., Goetz, S. and Hansen, M.C. (2012) Mapping and Monitoring Deforestation and Forest Degradation in Sumatra (Indonesia) Using Landsat Time Series Data Set from 1990 to 2010. Environmental Research Letter, 7, Article ID: 034010.

[21] Grinand, C., Rakotomalala, F., Gond, V., Vaudry, R., Bernoux, M. and Vieilledent, G. (2013) Estimating Deforestation in Tropical Humid and Dry Forests in Madagascar from 2000 to 2010 Using Multi-Date Landsat Satellite Images and the Random Forests Classifier. Remote Sensing of Environment, 139, 68-80.

https://doi.org/10.1016/j.rse.2013.07.008

[22] Holland, D.A., Boyd, D.S. and Marshall, P. (2006) Updating Topographic Mapping in Great Britain Using Imagery from High-Resolution Satellite Sensors. ISPRS Journal of Photogrammetry \& Remote Sensing, 60, 212-223. https://doi.org/10.1016/j.isprsjprs.2006.02.002

[23] Razafinimaro, A., Hajalalaina, A.R., Reziky, Z.T. and Delaitre, E. (2021) Formalization of Image Processing Chains for the Dynamics Forest Cover Using Landsat Satellite Multi-Sensor and Multi-Temporal. International Journal of Computer Trends and Technology, 69, 29-40.

[24] Butt, A., et al. (2015) Land Use Change Mapping and Analysis Using Remote Sensing and GIS: A Case Study of Simly Watershed, Islamabad, Pakistan. The Egyptian Journal of Remote Sensing and Space Sciences, 18, 251-259.

[25] Eckhardt, D.W., Verdin, J.P. and Lyford, G.R. (1990) Automated Update of an Irrigated Lands GIS Using SPOT HRV Imagery. Photogrammetric Engineering and Remote Sensing, 59, 1515-1522.

[26] Lounis, B. and Belhadj, A. (2005) Processus de correction radiométrique relative "PCRR" appliqué aux images Landsat TM multi-dates. The $3 \mathrm{rd}$ International Conference: Sciences of Electronic, Technologies of Information and Telecommunications (SETIT2005), Tunisia, 27-31 March 2005.

[27] Mohamed, N. and Mobarak, B. (2016) Change Detection Techniques Using Optical Remote Sensing: A Survey. American Scientific Research Journal for Engineering, Technology, and Sciences (ASRJETS), 17, 42-51.

[28] Razafinimaro, A., Hajalalaina, A.R., Reziky, Z.T., Delaitre, E. and Andrianarivo, A. (2021) Landsat8 Satellite Image Classification with ERDAS for Mapping the Kalambatritra Special Reserve. American Journal of Remote Sensing, 9, 16-22.

[29] Zhou, Q.M., Li, B.L. and Chen, Y.M. (2011) Remote Sensing Change Detection and Process Analysis of Long-Term Land Use Change and Human Impacts. AMBIO, 40, 807-818. https://doi.org/10.1007/s13280-011-0157-1

[30] Madhura, M. and Venkatazchalam, S. (2013) Comparison of Supervised Classification Methods on Remote Sensed Satellite Data: An Application in Chennai, South India. International Journal of Science and Research (IJSR), 4, 1407-1411.

[31] Al-Ahmadi, F.S. and Hames, A.S. (2009) Comparison of Four Classification Methods to Extract Land Use and Land Cover from Raw Satellite Images for Remote Arid Areas, Kingdom of Saudi Arabia. Journal of King Abdulaziz University, Earth Sciences, 20, 167-191.

[32] Haque, M.I. and Basak, R. (2017) Land Cover Change Detection Using GIS and Remote Sensing Techniques: A Spatio-Temporal Study on Tanguar Haor, Sunamganj, Bangladesh. The Egyptian Journal of Remote Sensing and Space Sciences, 20, 251-263. https://doi.org/10.1016/j.ejrs.2016.12.003 
[33] Mahendra, H.N., Mallikarjunaswamy, S., Rekha, V., Puspalatha, V. and Sharmila, N. (2019) Performance Analysis of Different Classifier for Remote Sensing Application. International Journal of Engineering and Advanced Technology (IJEAT), 9, 7153-7158.

[34] Jensen, J.R. (2005) Introductory Digital Image Processing, a Remote Sensing Perspective. Third Edition, Prentice Hall Series in Geographic Information Science, Prentice Hall, Hoboken.

[35] Singh, A., Singh, S., Garg, P.K. and Khanduric, K. (2013) Land Use and Land Cover Change Detection: A Comparative Approach Using Post Classification Change Matrix and Discriminate Function Change Detection Methodology of Allahabad City. International Journal of Current Engineering and Technology, 3, 142-148.

[36] Hexagon, Discriminant Function Change in ERDAS IMAGINE, 12 July (2019).

[37] Sarytany-Someah (2012) Atlas de la vulnerabilite sectorielle de la region vatovavy fitovinany, Photogrammétrie-topométrie-géodésie. 